\title{
Occurrence of enrofloxacin and ciprofloxacin residues in broiler meat sold in Sri Lanka
}

\author{
NB Karunarathna ${ }^{1}$, IA Perera ${ }^{2}$, NT Nayomi ${ }^{1}$, DMS Munasinghe ${ }^{3}$, SSP Silva ${ }^{4}$, I Strashnov ${ }^{4}$ and BR \\ Fernando $^{1^{*}}$ \\ ${ }^{1}$ Department of Veterinary Public Health and Pharmacology, Faculty of Veterinary Medicine and Animal Science, University of Peradeniya, \\ Peradeniya. \\ ${ }^{2}$ Government Veterinary Surgeon's Office, Serukele. \\ ${ }^{3}$ Department of Basic Veterinary Sciences, Faculty of Veterinary Medicine and Animal Science, University of Peradeniya, Peradeniya. \\ ${ }^{4}$ Department of Animal Production and Health, Peradeniya. \\ ${ }^{5}$ School of Chemistry, The University of Manchester, Oxford Road, Manchester, M13 9PL, United Kingdom.
}

Submitted: 06 August 2020; Revised: 19 April 2021; Accepted: 27 August 2021

\begin{abstract}
The presence of unacceptable levels of veterinary drug residues in animal-derived food is a global concern due to its negative impacts on human health. This study reports the occurrence and levels of two fluoroquinolone antimicrobialsenrofloxacin and ciprofloxacin-in broiler meat sold in Sri Lanka. A total of 129 broiler meat samples were purchased from the market, representing nine large-scale broiler meat processors (107 samples in 66 batches, branded) with an islandwide distribution and 22 small-scale processors (22 samples, unbranded). Enrofloxacin and ciprofloxacin in breast muscle were extracted following a previously published method with modifications and were subjected to High-Performance Liquid Chromatography with Fluorescence Detection analysis for the quantification of antimicrobials. Enrofloxacin residues were detected in $67(51.9 \%)$ samples, out of which 28 had quantifiable levels (1.7-578.6 $\mu \mathrm{g} \mathrm{kg}^{-1}$ ), whereas ciprofloxacin was detected in only nine samples. Only three samples $(2.3 \%)$ exceeded the European Union maximum residue limit of $100 \mu \mathrm{g} \mathrm{kg}^{-1}$ for the sum of ciprofloxacin and enrofloxacin in poultry muscle. These three samples had enrofloxacin in 130.3-578.6 $\mu \mathrm{g} \mathrm{kg}^{-1}$ range and ciprofloxacin in 15.7$28.8 \mu \mathrm{g} \mathrm{kg}^{-1}$ range. Mean enrofloxacin level in other samples was $5.9 \pm 5.3 \mu \mathrm{g} \mathrm{kg}^{-1}$. This study shows the widespread use of enrofloxacin in broiler meat industry in the country and the possibility of meat with harmful levels of residues entering the market. Thus, we highlight the need to establish regulations and a national-level veterinary drug residue surveillance program for animal-derived foods including broiler meat to ensure consumer safety.
\end{abstract}

Keywords: Broiler meat, ciprofloxacin, enrofloxacin, fluoroquinolone, HPLC, poultry, Sri Lanka.

\section{INTRODUCTION}

Poultry meat and eggs constitute two major animal protein sources for humans worldwide (Nkukwana, 2018). Rapid growth in global poultry production over the past few decades (McLeod et al., 2009) is partly attributed to the application of veterinary drugs for health management practices, such as therapy and prophylaxis, and for growth promotion of poultry birds (Singer \& Hofacre, 2006; Apata, 2009). However, irrational use of veterinary drugs can create a potential food safety risk for consumers via exposure to sub-therapeutic doses of drugs that may be present in animal-derived food (Darwish et al., 2013; Gouvea et al., 2015).

Enrofloxacin is a synthetic, second-generation fluoroquinolone antimicrobial used exclusively in veterinary practice (Ahn et al., 2012; Janecko et al., 2016). Mechanism of action of the drug is via inhibition of bacterial DNA gyrase (a type II topoisomerase), which results in interruption of the normal coiling of DNA, and rapid cell death (Mitchell, 2006). Its excellent activity against both Gram-positive and Gram-negative

*Corresponding author (ruchika@vet.pdn.ac.lk; (D) https://orcid.org/0000-0003-2972-1111) 
pathogens (Mitchell, 2006) has contributed to its widespread use in food-producing animals. In poultry industry, enrofloxacin is used to treat various respiratory and alimentary tract infections (Anderson et al., 2003; Javadi et al., 2011), including mycoplasmal infection, pasteurellosis (Bauditz, 1987), and colibacillosis (Huff et al., 2004), which is an economically devastating bacterial disease in poultry worldwide (Dziva \& Stevens, 2008). In many animal species, including poultry birds, enrofloxacin is biotransformed via de-ethylation to the primary metabolite ciprofloxacin (Seguin et al., 2004; Dimitrova et al., 2007; de Assis et al., 2016). Thus, animal-derived food obtained from farm animals treated with enrofloxacin can contain residues of both enrofloxacin and ciprofloxacin. Ciprofloxacin is also a broad-spectrum second-generation fluoroquinolone antimicrobial with a similar mechanism of action as enrofloxacin (Sharma et al., 2010). However, unlike enrofloxacin, ciprofloxacin is used in human medicine to treat infections of the urinary and respiratory tracts and skin, typhoid fever, and infectious diarrhea (King et al., 2000).

Many previous studies have documented the presence of residues of enrofloxacin and ciprofloxacin in poultry meat, including muscle tissue, liver and kidney (Amjad et al., 2005; Salehsadeh et al., 2007; Pena et al., 2010; Sattar et al., 2014; Sultan et al., 2014; Wang et al., 2015; Panzenhagen et al., 2016; Sarker et al., 2018). Human exposure to sub-therapeutic doses of veterinary drugs can be associated with several health hazards such as hypersensitivity reactions (Kowalski et al., 2005), carcinogenic, mutagenic, and teratogenic effects (Beyene, 2016; Manage 2018), and disruption of intestinal microflora (Dethlefsen et al., 2008). Moreover, continuous exposure to antimicrobial agents can promote development of antimicrobial-resistant strains of bacteria in humans (Landers et al., 2012; Gouvea et al., 2015; Manage, 2018), which has become a global health concern. In fact, fluoroquinolone-resistance in bacteria has been reported in many parts of the world (Endtz et al., 1991; Smith et al., 1999), which is of medical significance since fluoroquinolones are used in human therapy as well. Such resistant bacteria can act as reservoirs of genes conferring resistance to fluoroquinolones (Manage \& Liyanage, 2019), and these genes can be transmitted to other bacteria as well. Exposure of humans to ciprofloxacin through animal-derived food is also a major concern because it is one of the most widely used antimicrobials in the world (Sharma et al., 2010; Conley et al., 2018) and is also among the drugs of choice for human Campylobacter infection (McDermott et al., 2004).
To safeguard consumers from adverse effects, various countries and regulatory authorities have established Maximum Residue Limits (MRL) for enrofloxacin and ciprofloxacin. European Union, for example, has established an MRL of $100 \mu \mathrm{g} \mathrm{kg}^{-1}$ for the sum of enrofloxacin and ciprofloxacin in poultry muscle, skin and fat, and higher MRLs for poultry liver $\left(200 \mu \mathrm{g} \mathrm{kg}^{-1}\right)$, and kidney (300 $\mu \mathrm{g} \mathrm{kg}^{-1}$; European Commission, 2010). In comparison, Japan has set a much lower MRL $\left(10 \mu \mathrm{g} \mathrm{kg}^{-1}\right)$ for these substances in chicken tissue (Ministry of Health and Welfare, 2005), while the United States has banned the use of enrofloxacin in poultry, adopting a zero tolerance policy of the drug (FDA, 2005).

In Sri Lanka, poultry industry is the leading and fastest growing food animal sector (DAPH, 2019). It is dominated by chicken meat and egg production, while other sectors, such as turkeys, ducks, quail, and geese remain insignificant (DAPH, 2019). Chicken meat is the most widely consumed meat type in the country (De Silva et al., 2010), and per capita chicken availability has doubled from $4.9 \mathrm{~kg}$ to $10.4 \mathrm{~kg}$ during the last decade (DAPH, 2010; 2019). In addition, over $90 \%$ of the meatbased value-added products are manufactured using chicken meat (DAPH, 2019). With the heavy demand for poultry products, the country's broiler sector, together with the layer sector, has grown tremendously over the past few decades and has transitioned from a backyard system into a commercial industry (Wickramarachchi et al., 2017). Currently, around $80 \%$ of the poultry farms in the country operate at a commercial scale (Dandeniya et al., 2018), and have contributed to the self-sufficiency in chicken meat and egg production (DAPH, 2019).

Intensive poultry production in the country has inevitably resulted in the use of a variety of veterinary drugs including antimicrobials by the poultry farmers (Herath et al., 2015; 2016; Liyanage \& Pathmalal, 2017; Dandeniya et al., 2018; Lowe et al., 2019). Enrofloxacin is among the most widely used antimicrobials by the broiler farmers in Sri Lanka (Herath et al., 2015; 2016; Dandeniya et al., 2018). Enrofloxacin may be used alone or together with other antimicrobials such as amoxicillin (Dandeniya et al., 2018). Other antimicrobials commonly used for therapy and prophylaxis include sulfonamides, tylosin, and tetracyclines (Herath et al., 2016; Dandeniya et al., 2018; Lower et al., 2019). These antimicrobials are commonly administered to birds via drinking water (Herath et al., 2015). However, the use of antimicrobials as growth promoters in feed is now prohibited in the country (Goutard et al., 2017). 
Despite the extensive use of veterinary drugs, reports on their usage patterns are limited in Sri Lanka (Manage, 2018), and their presence in animal-derived food has been studied sparsely. Gunarathne et al. (2016) have analysed residues of five sulfonamides in broiler meat samples collected from eight districts and reported the presence of sulfadoxine and sulfadiazine in three and two samples, respectively, out of 72 samples tested, indicating the potential for commonly used drugs to present in poultry products. Lowe et al. (2019) have investigated the presence of eight antimicrobial residues, including ciprofloxacin, in broiler meat samples (muscle, liver and kidneys) from six large-scale broiler meat producers in the country using a bio-assay method and reported that detectable levels of residues were not found in any of the 252 samples tested.

Sri Lanka currently does not have regulations to control veterinary drug residues in animal-derived food, and no surveillance programs are in place to monitor antimicrobial residues in food. Therefore, studies pertaining to occurrence of veterinary drug residues in animal-derived food are important to ensure the consumer safety. Further, such studies will provide baseline information to employ a risk-based veterinary drug residue surveillance programmes in the country. The objective of this study was to document the occurrence and levels of enrofloxacin and its main metabolite ciprofloxacin in broiler meat sold in Sri Lanka. For that, broiler meat samples were collected from the market, representing both large-scale and small-scale broiler meat processors, and residues in breast muscle were determined, using High-Performance Liquid Chromatography with Fluorescence Detection.

\section{METHODOLOGY}

\section{Sample collection}

A total of 129 broiler meat samples (whole chicken) were collected representing large-scale broiler meat processors $(\mathrm{n}=9$, named $\mathrm{A}-\mathrm{I})$ producing an average of over 200 MT per month and small-scale processors $(n=22)$ in Sri Lanka from August 2018 to June 2019.

Large-scale processors provide the highest contribution to the broiler meat production in the country, and activities from pre-processing to packaging are carried out in semi-automated processing plants, where each slaughter batch include more than 1000 birds (Kottawatta et al., 2017). Broiler meats produced by these processors are available throughout the country under different brand names. From each large-scale processor, 5-23 whole chicken samples (510 batches) were collected comprising of a total of 107 samples ( 66 batches). The number of samples collected from each processor was nearly proportional to their monthly broiler meat production. Almost all of these large-scale processors are poultry buy-back operators, and therefore, a single batch of broiler meat may include broiler birds raised in different farms having different management practices. To account for this possibility, more than one sample from a single batch were purchased on several occasions.

Small-scale broiler meat processors often slaughter birds depending on the day-to-day requirement (Kottawatta et al., 2017), and broiler meats are sold without a brand name at their own retail shops closer to the farms. Twenty-two broiler meat samples from smallscale processors were collected from 22 different shops (1 sample from each processor) in three districts (Kandy, Colombo, and Kurunegala) to ensure a wider coverage of small-scale processors. Although these products did not have an expiry date, they were freshly slaughtered birds. After collection, about $100 \mathrm{~g}$ of the breast muscle was minced using a household grinder and stored at $-20^{\circ} \mathrm{C}$ until analysed. The breast muscle was used to determine the analytes of interest since the muscle tissues constitute the major edible portion in chicken and breast muscle is representative of all other muscle tissues in chickens (Lowe et al., 2019).

\section{Analytical method}

The method described by Yorke and Froc (2000) was used with some modifications. These modifications include increasing the sample weight from $0.5 \mathrm{~g}$ to $3 \mathrm{~g}$, and use of $6 \mathrm{~mL}$ of acetonitrile/acetone (70/30) as the extraction solvent instead of $200 \mu \mathrm{L}$ of acetonitrile used in the original method. These modifications were employed to improve the recovery of the method but had a limited success. Further, $2 \mathrm{~mL}$ of hexane was used in two consecutive rounds to remove the fat in the sample instead of one time $300 \mu \mathrm{L}$ of hexane used in the original method.

\section{Reference standards}

Analytical standards of enrofloxacin (purity $>98 \%$; catalogue no. 17849) and ciprofloxacin (VETRANAL ${ }^{\circledR}$; purity $=99 \%$; catalogue no. 33434) were purchased from Sigma-Aldrich (St Louis, MO, USA). 
Preparation of standard solutions and calibration standards

Stock standard solutions of enrofloxacin and ciprofloxacin $\left(100 \mathrm{mg} \mathrm{L}^{-1}\right)$ were prepared by dissolving $10 \mathrm{mg}$ of the compound with $100 \mu \mathrm{L}$ of $1 \mathrm{~mol} \mathrm{~L}^{-1} \mathrm{NaOH}$ and completing up to $100 \mathrm{~mL}$ with methanol (Yorke and Froc, 2000). Individual stock standard solutions were mixed and diluted with $0.05 \mathrm{~mol} \mathrm{~L}^{-1}$ tris(hydroxymethyl) aminomethane buffer ( $\mathrm{pH}$ 9.1), hereafter referred to as tris buffer, to prepare a mixed standard solution containing enrofloxacin and ciprofloxacin (each at $1 \mathrm{mg} \mathrm{L}^{-1}$ ), which was used to spike the quality control samples and to prepare calibration standards. This study employed an external calibration methodology, and calibration standards $\left(1,5,10,25,50,100,150\right.$ and $\left.200 \mu \mathrm{g} \mathrm{L}^{-1}\right)$ were prepared by diluting the mixed standard solution (1 mg L ${ }^{-1}$ ) with tris buffer. Stock standard solutions of enrofloxacin and ciprofloxacin were stable for at least eight months when stored at $-20^{\circ} \mathrm{C}$ without exposure to light. Both the mixed standard solution $\left(1 \mathrm{mg} \mathrm{L}^{-1}\right)$ and calibration standards were prepared freshly before the analysis.

\section{Quality control samples}

Quality control samples were prepared by spiking drugfree breast muscle samples, purchased from a reliable source, and confirmed by analysing with LC-MS/MS, for the absence of enrofloxacin and ciprofloxacin residues. The blank samples were spiked with both analytes at final tissue concentrations of 50, 100 and $150 \mu \mathrm{g} \mathrm{kg}^{-1}$ that are equivalent to $0.5 \times \mathrm{MRL}, \mathrm{MRL}$ and $1.5 \times \mathrm{MRL}$, respectively established for poultry muscle by the European Union (European Commission, 2002).

\section{Sample extraction}

Frozen minced breast muscle samples were allowed to thaw at room temperature, and $3.00 \pm 0.05 \mathrm{~g}$ of the sample was weighed. Then, $1800 \mu \mathrm{L}$ tris buffer was added to the sample and allowed to stand at room temperature for $10 \mathrm{~min}$. For the quality control samples, to which 150 , 300 or $450 \mu \mathrm{L}$ of mixed standard solution $\left(1 \mathrm{mg} \mathrm{L}^{-1}\right)$ had been added, only 1650,1500 or $1350 \mu \mathrm{L}$ of tris buffer was added, respectively. Then, $6 \mathrm{~mL}$ of acetonitrile/ acetone $(70 / 30, \mathrm{v} / \mathrm{v})$ was added, and the sample was homogenized for $1 \mathrm{~min}$ using a tissue homogenizer (Ultra $\operatorname{Turrax}^{\circledR}$ T 25 basic; IKA ${ }^{\circledR}$ Werke GmbH \& Co. KG, Staufen, Germany). The homogenate was centrifuged at $4,000 \mathrm{~g}$ for $10 \mathrm{~min}$, and $2.6 \mathrm{~mL}$ of the supernatant was transferred to a glass tube and evaporated at $50^{\circ} \mathrm{C}$ under mild flow of $\mathrm{N}_{2}$ (purity $=99.95 \%$ ), using a dry block incubator with a sample concentrator (Dri-Block ${ }^{\circledR}$ DB-3A, Techne Ltd., Cambridge, UK). The dry residue was resuspended in $1.5 \mathrm{~mL}$ of tris buffer solution, and vortexed for $10 \mathrm{~s}$. The resuspended sample was defatted twice by adding $2 \mathrm{~mL}$ of $\mathrm{n}$-hexane, vortexing for $30 \mathrm{~s}$ and discarding the upper hexane layer. Next, $0.5 \mathrm{~mL}$ of n-hexane was added to the sample and vortexed for $30 \mathrm{~s}$. The sample was transferred to a 2-mL microcentrifuge tube, and then was centrifuged at $17,000 \mathrm{~g}$ for $5 \mathrm{~min}$. Finally, $750 \mu \mathrm{L}$ of the bottom aqueous layer was filtered through a $0.45-\mu \mathrm{m}$ PVDF syringe-driven filter, and the filtrate was transferred to an amber coloured autosampler vial for injection into the HPLC system (dilution factor $=1.5)$.

A negative control (blank breast muscle sample) and a blank sample spiked with enrofloxacin and ciprofloxacin, each at $100 \mu \mathrm{g} \mathrm{kg}^{-1}$, were run with each batch of samples for recovery calculation. If antimicrobial levels in the samples exceeded the European Union MRL of $100 \mu \mathrm{g} \mathrm{kg}^{-1}$, those samples were confirmed by repeating the analysis.

\section{High-performance liquid chromatography- fluorescence detection (HPLC-FLD) analysis}

The HPLC analysis was performed using an Agilent 1100 series HPLC system (Agilent Technologies, Waldbronn, Germany) consisting of a micro vacuum degasser (G1379A), quaternary pump (G1311A), autosampler (G1313A), thermostatted column compartment (G1316A) and a fluorescence detector (G1321A, Agilent 1200 series). The mobile phase was a mixture of $0.02 \mathrm{~mol} \mathrm{~L}^{-1} \mathrm{H}_{3} \mathrm{PO}_{4} /$ acetonitrile $(85 / 15, \mathrm{v} / \mathrm{v}$; Yorke \& Froc, 2000) and was delivered isocratically at a flow rate of

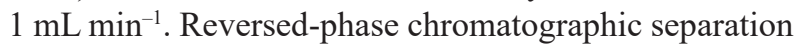
(Yorke \& Froc, 2000) was performed on a C18 analytical column (Zorbax Eclipse XDB-C18, $4.6 \times 150 \mathrm{~mm}$, particle size $5 \mu \mathrm{m}$; Agilent Technologies, CA, USA). The analytical column was maintained at $50^{\circ} \mathrm{C}$ and was fitted with a guard column (Zorbax SB-C18, $4.6 \times 12.5 \mathrm{~mm}$, particle size $5 \mu \mathrm{m}$; Agilent Technologies, CA, USA) for protection. The injection volume of the sample was $20 \mu \mathrm{L}$, and the total run time was $10 \mathrm{~min}$. Excitation and emission wavelengths for fluorescence detection were set at $280 \mathrm{~nm}$ and $450 \mathrm{~nm}$, respectively (Yorke \& Froc, 2000). ChemStation for LC3D software (Rev. A. 10.02) was used to control the HPLC system and analyse the output data. 


\section{Method validation}

\section{Linearity}

Linearity of the analytical method was determined over the 1-200 $\mu \mathrm{g} \mathrm{L}^{-1}$ concentration range for each analyte, using the external calibration standards. The linearity of the standard curve was expressed using coefficient of determination $\left(\mathrm{R}^{2}\right)$ obtained through the least square linear regression.

\section{Selectivity}

Blank breast muscle samples from different sources were analysed to assess matrix interference and presence/absence of co-eluting endogenous compounds at the retention times of the two analytes. In addition, chromatographic selectivity was also assessed by calculating the resolution of the enrofloxacin and ciprofloxacin peaks following the equation given below (USFDA, 1994).

$$
R_{S}=\frac{t_{R B}-t_{R A}}{0.85\left(W_{0.5 B}+W_{0.5 A}\right)}
$$

where, $\mathrm{Rs}=$ peak resolution, $\mathrm{t}_{\mathrm{RB}}=$ retention time of peak $2, \mathrm{t}_{\mathrm{RA}}=$ retention time of peak $1, \mathrm{~W}_{0.5 \mathrm{~B}}=$ width of peak 2 at half peak height, and $\mathrm{W}_{0.5 \mathrm{~A}}=$ width of peak 1 at half peak height.

\section{Trueness (Recovery)}

The trueness of measurements was assessed through recovery of analytes spiked into a blank matrix. Blank breast muscle samples were spiked with the two analytes at $0.5 \times \mathrm{MRL}, \mathrm{MRL}$, and $1.5 \times \mathrm{MRL}$ as per the validation requirements of Commission Decision 2002/657/EC (European Commission, 2002). Mean recovery at each spike level was calculated from nine replicates that were run on three different days.

\section{Precision}

Precision of the analytical procedure was determined at two levels: repeatability (intra-assay precision) and intermediate precision (within-laboratory reproducibility). To determine repeatability, blank muscle samples spiked with the two analytes at 50, 100, and $150 \mu \mathrm{g} \mathrm{kg}^{-1}$ were analysed on the same day. Intermediate precision was determined by analysing spiked samples on three different days. Precision was expressed as the percent relative standard deviation ( $\mathrm{RSD} \%$ ) of measured concentration of analytes.

\section{Limit of detection and limit of quantification}

Chromatograms of blank muscle samples were analysed, and signal-to-noise ratio of three and ten were considered as limit of detection (LOD) and limit of quantification (LOQ), respectively at the retention time windows of the two analytes.

\section{Decision limit (CC $\alpha)$ and detection capability (CCß)}

Blank breast muscle samples spiked with enrofloxacin and ciprofloxacin, each at $100 \mu \mathrm{g} \mathrm{kg}^{-1}$ (i.e., MRL), were analysed, and decision limit ( $\mathrm{CC} \alpha$ ) was calculated as the concentration at the permitted limit plus 1.64 times the corresponding standard deviation (i.e., $\mathrm{CC} \alpha=\mathrm{MRL}+$ 1.64SD, $\alpha=5 \%$ ). To determine the detection capability $(\mathrm{CC} \beta)$, blank breast muscle samples spiked with enrofloxacin and ciprofloxacin at respective $\mathrm{CC} \alpha$ values were analysed, and $C C \beta$ was calculated as the value of the $\mathrm{CC} \alpha$ plus 1.64 times the corresponding standard deviation (i.e., $\mathrm{CC} \beta=\mathrm{CC} \alpha+1.64 \mathrm{SD}, \beta=5 \%$ ).

\section{Statistical analysis}

Descriptive statistics, including mean, standard deviation, minimum and maximum were calculated for enrofloxacin and ciprofloxacin levels in samples above the limit of quantification. Enrofloxacin level was compared between large-scale and small-scale processors, using one-way analysis of variance (ANOVA). Before conducting ANOVA, normality of the data and homogeneity of variances were verified $(p>0.05)$ using Shapiro-Wilk and Levene's tests, respectively. Statistical analyses were conducted using Minitab 17 statistical software (Minitab Inc., State college, PA, USA) with the level of significance set at 0.05 .

\section{RESULTS AND DISCUSSION}

\section{Method validation}

The HPLC-FLD method separated ciprofloxacin and enrofloxacin within less than $8 \mathrm{~min}$, and the respective analytes were eluted with a mean retention time \pm standard deviation (SD) of $5.64 \pm 0.08 \mathrm{~min}$ and $7.25 \pm 0.13 \mathrm{~min}$ (Figure 1). Both peaks had an acceptable symmetry and were well separated from each other with a resolution of 5.6, which is higher than the minimum recommended resolution of 2 between the peaks of interest (USFDA, 1994). Chromatograms of blank muscle samples did not have any co-eluting peaks at the retention times of the 
two analytes (Figure 1), which indicates the selectivity of the analytical method for the two target analytes.
All the matrix peaks eluted within five minutes of sample injection.

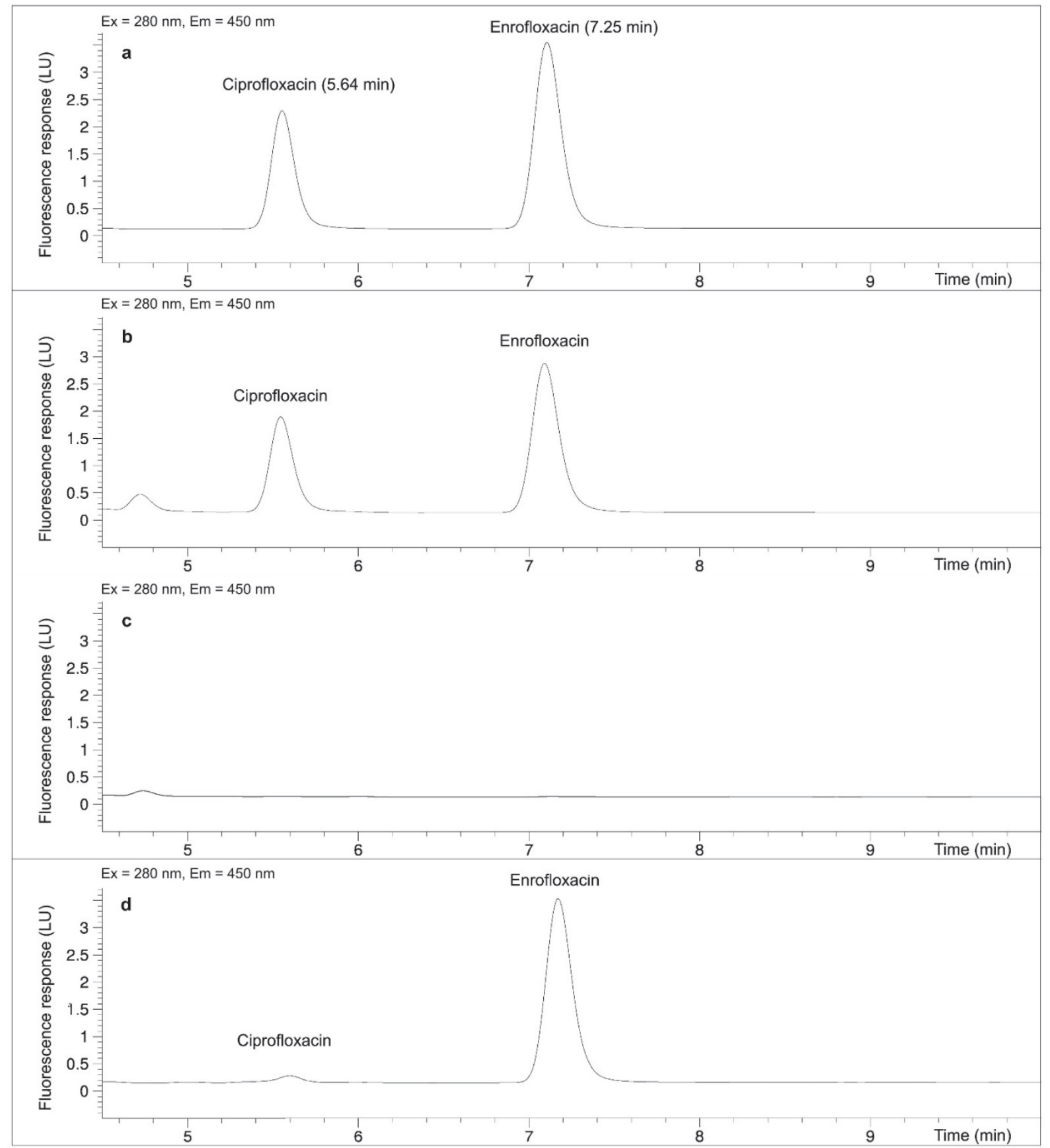

Figure 1: HPLC-FLD chromatograms. (a) Calibration standard solution containing ciprofloxacin and enrofloxacin, each at $50 \mu \mathrm{g} \mathrm{L} \mathrm{L}^{-1}$. Retention time is given in parentheses; (b) Broiler breast muscle sample spiked with ciprofloxacin and enrofloxacin, each at $100 \mu \mathrm{g} \mathrm{kg}^{-1}$; (c) Blank broiler muscle sample showing absence of endogenous compounds in the matrix at the retention times of two analytes; (d) A broiler breast muscle sample that exceeded European Union MRL $\left(100 \mu \mathrm{g} \mathrm{kg}^{-1}\right)$ for the sum of enrofloxacin and ciprofloxacin in poultry muscle, showing the presence of both ciprofloxacin and enrofloxacin (LU = luminescence unit; dilution factor is 1.5 for $\mathrm{b}$ and $\mathrm{c}$; dilution factor is 3 for $\mathrm{d}$ ). 
Table 1: Performance characteristics of the analytical method for determination of residues of enrofloxacin and ciprofloxacin in broiler breast muscle

\begin{tabular}{lcccccccc}
\hline Analyte & $\begin{array}{c}\text { Spiked level } \\
\left(\mu \mathrm{gg}^{-1}\right)\end{array}$ & $\begin{array}{c}\text { Mean recovery } \\
\pm \mathrm{SD}(\%)^{\mathrm{a}}\end{array}$ & $\begin{array}{c}\mathrm{RSD}_{\mathrm{r}} \\
(\%)\end{array}$ & $\begin{array}{c}\mathrm{RSD}_{\mathrm{i}} \\
(\%)\end{array}$ & $\begin{array}{c}\mathrm{LOD} \\
\left(\mu \mathrm{g} \mathrm{kg}^{-1}\right)\end{array}$ & $\begin{array}{c}\mathrm{LOQ} \\
\left(\mu \mathrm{gg}^{-1}\right)\end{array}$ & $\begin{array}{c}\mathrm{CC} \alpha \\
\left(\mu \mathrm{gg}^{-1}\right)\end{array}$ & $\begin{array}{c}\mathrm{CC} \beta \\
\left(\mu \mathrm{g} \mathrm{kg}^{-1}\right)\end{array}$ \\
\hline \multirow{3}{*}{ Enrofloxacin } & 50 & $63.3 \pm 7.1$ & 12.3 & 11.2 & & & & \\
& 100 & $63.1 \pm 7.1$ & 9.0 & 11.2 & 0.5 & 1.6 & 111.6 & 113.1 \\
& 150 & $62.0 \pm 7.7$ & 8.8 & 12.5 & & & & 111.2 \\
Ciprofloxacin & 50 & $58.6 \pm 4.0$ & 7.9 & 6.9 & & & & \\
& 100 & $60.9 \pm 5.2$ & 7.2 & 8.5 & 2.2 & 7.5 & 108.5 & 11.2 \\
\hline
\end{tabular}

${ }^{a}$ mean recovery from nine replicates

$\mathrm{RSD}_{\mathrm{r}}$ - repeatability; RSD - intermediate precision; LOD - limit of detection; LOQ - limit of quantification; CC $\alpha$ - decision limit; $\mathrm{CC} \beta$ - detection capability; SD - standard deviation

Standard curves for enrofloxacin and ciprofloxacin demonstrated a good linearity over the $1-200 \mu \mathrm{g} \mathrm{L}^{-1}$ concentration range with coefficients of determination $\left(\mathrm{R}^{2}\right)$ above 0.998 , indicating sufficient linearity of the present analytical method. Mean recovery of enrofloxacin at the three spike levels (i.e., 50, 100, and $150 \mu \mathrm{g} \mathrm{kg}^{-1}$ ) ranged between $62.0-63.3 \%$, while that of ciprofloxacin varied between $58.6-60.9 \%$ (Table 1). Similar relatively low recoveries have been reported by several other authors who have used similar extraction procedure to determine quinolones in meat (Yorke \& Froc, 2000; Kirbiš et al., 2005). This relatively low recovery rate of the analytical method could affect detection of very low levels of analytes $\left(<0.8 \mu \mathrm{g} \mathrm{kg}^{-1}\right.$ of enrofloxacin and $<3.7 \mu \mathrm{g} \mathrm{kg}^{-1}$ of ciprofloxacin) in the samples.

Repeatability RSD\% for enrofloxacin and ciprofloxacin at the three spike levels were in the ranges of $8.8-12.3 \%$ and $4.4-7.9 \%$, respectively, with lower RSD\% values observed at higher spike levels (Table 1). Intermediate precision RSD\% for the two analytes at three spike levels varied between 4.9 and $12.5 \%$. According to the guidelines of Commission Decision 2002/657/ $\mathrm{EC}$, intermediate precision RSD\% should not exceed the RSD\% calculated by the Horwitz equation, and the repeatability RSD\% should not exceed two thirds of the RSD\% calculated by the Horwitz equation (European Commission, 2002). The repeatability $\mathrm{RSD} \%$ and intermediate precision $\mathrm{RSD} \%$ of the present analytical method met these performance criteria, indicating acceptable precision, as the RSD\% values calculated by Horwitz equation were 25.1, 22.6, and $21.3 \%$ for 50 , 100 , and $150 \mu \mathrm{g} \mathrm{kg}^{-1}$ levels, respectively.

Based on the signal-to-noise ratio method, limit of detection (LOD) and limit of quantification (LOQ) of enrofloxacin were 0.5 and $1.6 \mu \mathrm{g} \mathrm{kg}^{-1}$, respectively, while those of ciprofloxacin were comparatively higher (2.2 and $7.5 \mu \mathrm{g} \mathrm{kg}^{-1}$ ). The LODs and LOQs obtained for the two analytes were sufficiently below the European Union $\operatorname{MRL}\left(100 \mu \mathrm{g} \mathrm{kg}^{-1}\right)$ and even Japanese MRL $\left(10 \mu \mathrm{g} \mathrm{kg}^{-1}\right)$. These LODs and LOQs are similar to those reported by Yorke and Froc (2000). Decision limits (CC $\alpha$ ) for enrofloxacin and ciprofloxacin were $111.6 \mu \mathrm{g} \mathrm{kg}^{-1}$ and $108.5 \mu \mathrm{g} \mathrm{kg}^{-1}$ respectively, and detection capabilities (CC $\beta$ ) were $113.1 \mu \mathrm{g} \mathrm{kg}^{-1}$ and $111.2 \mu \mathrm{g} \mathrm{kg}^{-1}$ for the respective analytes. These $\mathrm{CC} \alpha$ and $\mathrm{CC} \beta$ of the two analytes are also comparable with those reported in other similar studies (de Assis et al., 2016).

\section{Occurrence of enrofloxacin and ciprofloxacin in broiler muscle}

The study revealed that 67 (51.9\%) out of the 129 broiler breast muscle samples were positive for residues of enrofloxacin $\left(\right.$ range $=$ LOD-578.6 $\left.\mu \mathrm{g} \mathrm{kg}^{-1}\right)$. Enrofloxacin was detected in samples from both large-scale (50.5\%) and small-scale $(59.1 \%)$ broiler meat processors. In each large-scale processor, $40.0-69.6 \%$ of the samples became positive for enrofloxacin, except in one processor (Table 2). Three breast muscle samples - one from a largescale processor and two from small-scale processorshad residues of enrofloxacin above the European Union MRL of $100 \mu \mathrm{g} \mathrm{kg}^{-1}$ (Figure 2; Table 3). The mean concentration of enrofloxacin was $5.9 \pm 5.3 \mu \mathrm{g} \mathrm{kg}^{-1}$ (range $=1.7-19.3 \mu \mathrm{g} \mathrm{kg}^{-1}$ ) in breast muscle samples with quantifiable enrofloxacin levels (excluding the samples that exceeded the MRL of $100 \mu \mathrm{g} \mathrm{kg}^{-1}$ ). The mean enrofloxacin levels did not differ significantly between the large-scale processors $\left(6.6 \pm 5.9 \mu \mathrm{g} \mathrm{kg}^{-1}\right)$ and the small-scale processors $\left(3.7 \pm 2.2 \mu \mathrm{g} \mathrm{kg}^{-1}\right.$; one way ANOVA, $\left.\mathrm{F}_{1,23}=1.34, \mathrm{p}=0.259\right)$. 
Table 2: Occurrence of residues of enrofloxacin and ciprofloxacin in broiler breast muscle collected from nine large-scale (A-I) and small-scale broiler meat processors

\begin{tabular}{cccccc}
\hline Broiler meat processor & $\begin{array}{c}\text { No. of samples } \\
\text { analysed }\end{array}$ & $\begin{array}{c}\text { No. of positive } \\
\text { samples }^{\mathrm{a}}\end{array}$ & $\begin{array}{c}\text { Percentage of } \\
\text { positive samples } \\
(\%)\end{array}$ & $\begin{array}{c}\text { Ciprofloxacin } \\
\text { No. of positive } \\
\text { samples }^{\text {a }}\end{array}$ & $\begin{array}{c}\text { Percentage of } \\
\text { positive samples } \\
(\%)\end{array}$ \\
\hline A & 23 & 16 & 69.6 & 0 & 0.0 \\
B & 15 & 6 & 40.0 & 1 & 6.7 \\
C & 15 & 8 & 53.3 & 0 & 0.0 \\
D & 12 & 7 & 58.3 & 1 & 8.3 \\
E & 12 & 6 & 50.0 & 0 & 0.0 \\
F & 10 & 1 & 10.0 & 0 & 0.0 \\
G & 10 & 5 & 50.0 & 2 & 0.0 \\
H & 5 & 2 & 40.0 & 0 & 0.0 \\
I & 5 & 3 & 60.0 & 0 & 20.0 \\
Small-scale processors & 22 & 13 & 59.1 & 5 & 7.0 \\
\hline
\end{tabular}

anumber of samples above LOD

Table 3: Residue levels of enrofloxacin and ciprofloxacin in the three broiler breast muscle samples that exceeded European Union MRL of $100 \mu \mathrm{g} / \mathrm{kg}$ for sum of ciprofloxacin and enrofloxacin in poultry meat

\begin{tabular}{ccccc}
\hline Sample & $\begin{array}{c}\text { Type of } \\
\text { processor }\end{array}$ & $\begin{array}{c}\text { Ciprofloxacin } \\
\text { level }\left(\mu \mathrm{kg}^{-1}\right)\end{array}$ & $\begin{array}{c}\text { Enrofloxacin level } \\
\left(\mu \mathrm{kg}^{-1}\right)\end{array}$ & $\begin{array}{c}\text { Sum of enrofloxacin and } \\
\text { ciprofloxacin }\left(\mu \mathrm{g} \mathrm{kg}^{-1}\right)\end{array}$ \\
\hline 1 & Small-scale & 15.9 & 130.3 & 146.2 \\
2 & Small-scale & 15.7 & 259.2 & 274.9 \\
3 & Large-scale & 28.8 & 578.6 & 607.4 \\
\hline
\end{tabular}

Ciprofloxacin residues were detected (i.e., above the LOD) in nine (7.0\%) out of 129 breast muscle samples (Table 2). Five of these samples belonged to small-scale broiler meat processors, and the remaining four belonged to large-scale processors. Ciprofloxacin residues could be quantified only in the three samples that had enrofloxacin residue levels above the European Union MRL. Ciprofloxacin levels in those three samples ranged from $15.7-28.8 \mu \mathrm{g} \mathrm{kg}^{-1}$ (mean $\pm \mathrm{SD}=20.1 \pm 7.5 \mu \mathrm{g} \mathrm{kg}{ }^{-1}$ ). Ciprofloxacin residue levels were 8-20 times lower than the enrofloxacin levels in those three samples.

The presence of enrofloxacin in $51.9 \%$ of the breast muscle samples and detection of enrofloxacin in both large- and small-scale broiler meat processors indicate the widespread use of enrofloxacin by broiler farmers. There are previous reports on high usage of enrofloxacin by broiler farmers in Sri Lanka (Herath et al., 2015;
2016; Dandeniya et al., 2018). For example, enrofloxacin was found to be the most widely used antimicrobial in broiler farms associated with large-scale companies and medium-scale broiler farms (Dandeniya et al., 2018). Previous studies conducted elsewhere have also reported the presence of enrofloxacin residues in broiler meat. The occurrence of enrofloxacin in breast muscle samples in our study (51.9\%) is similar to that of Aslam et al. (2016), who reported that $52 \%$ of broiler muscle had residues of enrofloxacin in a study conducted in Pakistan. However, various studies have reported occurrences of enrofloxacin in broiler meat that are different from the present study [e.g., 5\% by Wang et al. (2015), 18\% by Sattar et al. (2014), 21\% by Sarkeret al. (2018), 22\% by Panzenhagen et al., (2016), 33\% by Pena et al. (2010), and $90 \%$ by Attari et al. (2014)] with occurrence reaching up to $100 \%$ in certain studies (Salehzadeh et al., 2007). 


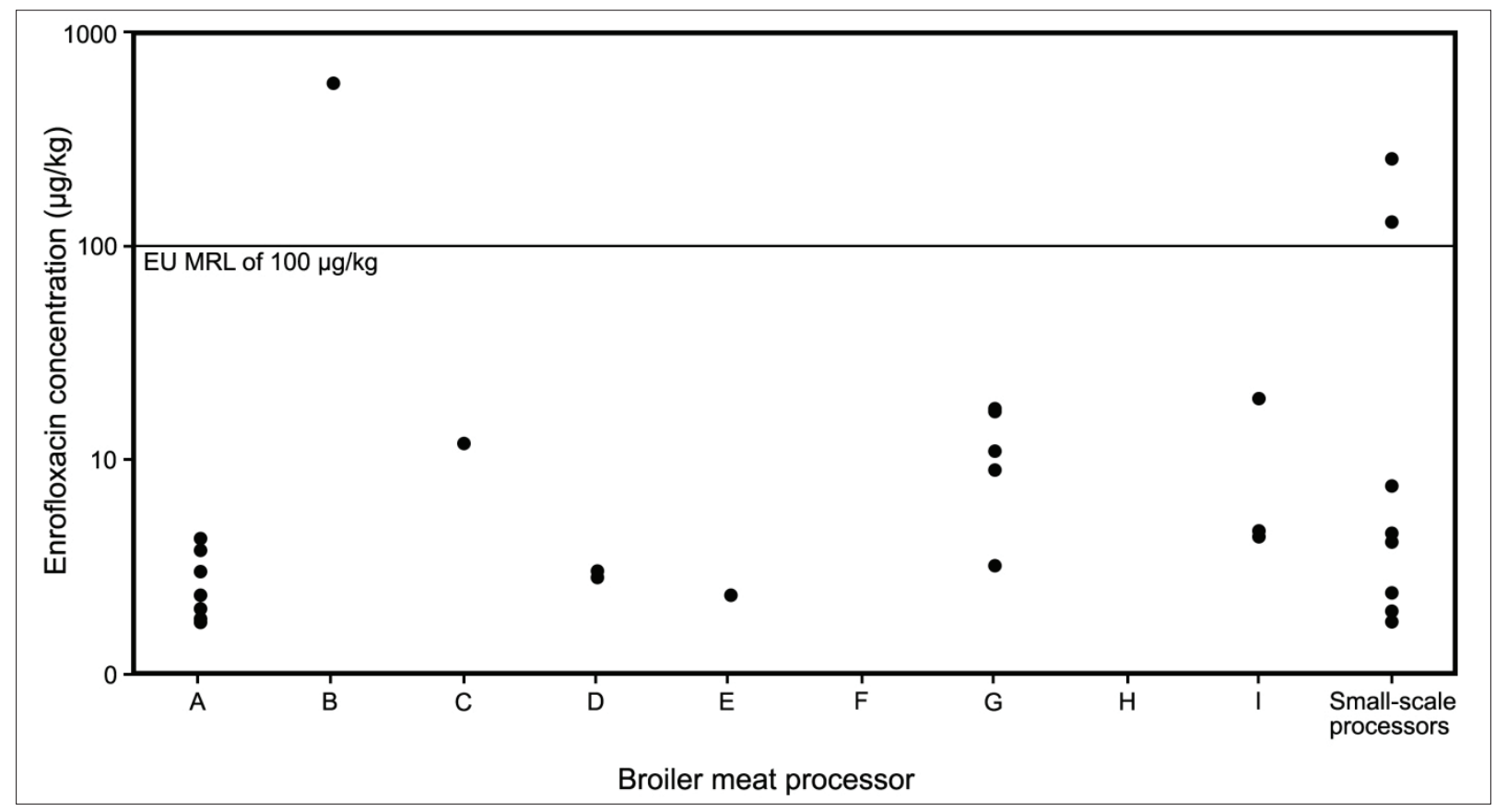

Figure 2: Levels of enrofloxacin (samples with quantifiable levels) in broiler muscle samples from large-scale processors and smallscale processors.

Ciprofloxacin is the main metabolite of enrofloxacin (Seguin et al., 2004; Dimitrova et al., 2007; de Assis et al., 2016) and can occur in animal-derived food obtained from farm animals treated with enrofloxacin (Amjad et al., 2005). In a pharmacokinetics study, where chickens were treated with enrofloxacin at $10 \mathrm{mg} \mathrm{kg}^{-1}$ body weight, de Assis et al. (2016) found that ciprofloxacin levels in muscle tissue (44.6-241.7 $\mu \mathrm{g} \mathrm{kg}^{-1}$ ) were 7-12 times lower than the corresponding enrofloxacin levels (484.1-2941.8 $\mu \mathrm{g} \mathrm{kg}^{-1}$ ) and that ciprofloxacin levels became undetectable when enrofloxacin levels were around $\sim 6 \mu \mathrm{g} \mathrm{kg}^{-1}$. This explains the low levels of ciprofloxacin (15.7-28.8 $\mu \mathrm{g} \mathrm{kg}^{-1}$ ), which were 8-20 times lower compared to enrofloxacin levels (130.3$578.6 \mu \mathrm{g} \mathrm{kg}^{-1}$ ) in our study, and the low occurrence of ciprofloxacin $(7.0 \%)$ in breast muscle samples compared to enrofloxacin $(51.9 \%)$. Our results are consistent with other studies that have shown both low occurrence and low levels of ciprofloxacin compared with enrofloxacin in broiler meat (Amjad et al., 2005; Pena et al., 2010, Moghadam et al., 2018; Sureshkumar \& Sarathchandra, 2018; Arsland-acroz \& Sozbilir, 2020). Previously Lowe et al. (2019) have analysed ciprofloxacin in broiler meat samples (muscle, liver, and kidney) collected from Sri Lanka using a bioassay method, but ciprofloxacin residues were not detected in any of the 252 samples analysed. It is possible that Lowe et al. (2019) did not find ciprofloxacin residues due to the employment of a screening bioassay technique in which the sensitivity is relatively low.

The three broiler breast muscle samples that exceeded the European Union MRL of $100 \mu \mathrm{g} \mathrm{kg}^{-1}$ for the sum of enrofloxacin and ciprofloxacin in poultry muscle indicate incorrect use, and possibly abuse of enrofloxacin by certain broiler farmers. Misuse of veterinary drugs is a common problem in the animal production systems, and enrofloxacin levels above the MRLs in broiler meat have been reported in several countries including Pakistan (Aslam et al., 2016), Portugal (Pena et al., 2010) and Iran (Salehzadeh et al., 2007). However, the situation of the broiler meat industry in Sri Lanka, as revealed by our study, is better compared with the broiler meat industry reported in the study of Aslam et al. (2016), in which 21 (28\%) out of 75 broiler meat samples had enrofloxacin above the MRL.

The European Medicine Agency recommends a withdrawal period of 3 days for chickens treated with enrofloxacin at a dosage of $10 \mathrm{mg} \mathrm{kg}{ }^{-1}$ body weight (EMA, 2012). This 3-day withdrawal period has been shown to be adequate for the enrofloxacin levels in 
chicken muscle tissue to deplete not only below the European Union MRL of $100 \mu \mathrm{g} \mathrm{kg}^{-1}$ but also below the Japanese MRL of $10 \mu \mathrm{g} \mathrm{kg}^{-1}$ (Shim et al., 2013; de Assis et al., 2016). In broiler farms in Sri Lanka, birds are treated with antimicrobials within the first 5-6 days of age and then during 18-24 days of age, and the birds are usually slaughtered around 35-36 days of age (Lowe et al., 2019). Therefore, this practice, which includes a $\sim 10$-day drug-free period, alone should be adequate to prevent the occurrence of enrofloxacin levels above the MRL in broiler meat. However, the enrofloxacin levels (130.3-578.6 $\mathrm{g} \mathrm{kg} \mathrm{k}^{-1}$ ) exceeding the MRL in our study indicate that the broiler birds have been treated within three days of the planned slaughter, or birds have been treated with a higher dose of enrofloxacin than the recommended dose. However, it is difficult to predict the exact cause for the higher enrofloxacin levels without examining the treatment records of birds. Misuse of veterinary drugs can occur in broiler farms in Sri Lanka due to the lack of knowledge on the importance of adhering to withdrawal periods (Lowe et al., 2019) and the use of antimicrobials without professional advice (Karunarathna et al., 2013; Herath et al., 2015).

In our study, $97.7 \%$ of breast muscle samples had no enrofloxacin or enrofloxacin levels below the MRL of $100 \mu \mathrm{g} \mathrm{kg}^{-1}$ indicating that these products are within safe limits for human consumption from a toxicological point of view. Nevertheless, widespread use of enrofloxacin in broiler meat industry, as evident from our study, may have important implications on development of antimicrobial resistance in bacteria. Development fluoroquinolone-resistance is well known in Campylobacter sp., which is a major cause of foodborne illnesses worldwide (Tauxe, 2002). In several parts of the world, authorization of enrofloxacin in poultry was found to be responsible for the emergence of fluoroquinolone-resistant Campylobacter sp. (Endtz et al., 1991; Smith et al., 1999). In the United States, such fluoroquinolone-resistant Campylobacter isolates were found to have transferred to humans, causing fluoroquinolone-resistant Campylobacter infections, and consequently, the US banned the use of fluoroquinolones in poultry industry in 2005 (Nelson et al., 2007). In Sri Lanka also, emergence of such resistance remains a possibility because of the widespread use of enrofloxacin and high prevalence of Campylobacter in broiler flocks and chicken meat in the retail market (Kalupahana et al., 2013, 2018; Kottawatta et al., 2017). In fact, some studies have shown that more than $80 \%$ of Campylobacter isolates obtained from broiler birds and chicken meat in Sri Lanka were resistant to quinolones (Kottawatta et al., 2017). In addition to Campylobacter sp., resistance to fluoroquinolones has been observed in Escherichia coli isolated from chickens as well (Dissnayake \& Wijewardana, 2005). Bacteria resistant to enrofloxacin have been reported in poultry litter and poultry manure in Sri Lanka (Herath et al., 2015; 2016; Lowe et al., 2019). The practice of using poultry manure as fertilizers in vegetable cultivation (Herath et al., 2015; 2016), can contribute to spread of antimicrobial resistance in the environment (Dandeniya et al. 2018). Wastewater from poultry farms can spread not only antimicrobials into the environment but also antimicrobial-resistant bacteria as well (Liyanage \& Pathmalal, 2017).

Although many countries have regulations to control veterinary drug residues including fluoroquinolones in animal-derived food (European Commission, 2010), Sri Lanka currently does not have such regulations/ legislations. As a result, poultry processors are not required to test their products for presence of veterinary drug residues. Our study, in which $2.3 \%$ of broiler meat samples had enrofloxacin levels exceeding the European Union MRL, indicates the possibility of broiler meat with harmful levels of drug residues entering the market. Therefore, it is important to establish regulations and surveillance programmes to ensure the chemical safety of animal-derived food in the country and to improve consumer confidence. Many broiler farms associated with large-scale companies in the country have discontinued or minimized the use of tetracyclines as its extensive use has led to the development of resistance in bacteria (Dandeniya et al., 2018; Lowe et al., 2019). Given the level of resistance building up in bacteria against enrofloxacin, it has been suggested that poultry industry in Sri Lanka will have to abandon the use of enrofloxacin in the near future (Dandeniya \& Caucci, 2020). Therefore, a mechanism is required to monitor the usage of veterinary drugs in the country and to ensure prudent use of antimicrobials in the animal production by educating the farmer community.

\section{CONCLUSION}

This study reports a high occurrence of fluoroquinolone residues, especially enrofloxacin, in broiler meat with an occasional violation of MRLs established elsewhere. Therefore, it is necessary to establish regulations in Sri Lanka (including MRLs) to control veterinary drug resides in animal-derived food and a risk-based surveillance program to ensure consumer safety and build consumer confidence which in turn will benefit the poultry industry. Further, prudent use of antimicrobials in animal-derived food is essential to combat development of antimicrobial 
resistance against valuable antimicrobials reserved for human medicine such as ciprofloxacin.

\section{Competing interest}

Authors declare none.

\section{Acknowledgements}

Authors thank Innovation Commercialization Enhancement (ICE) grant of the Faculty of Veterinary Medicine and Animal Science (6026-LK/8743-LK) under the Accelerating Higher Education Expansion and Development project of the Ministry of Higher Education, Sri Lanka. Authors also thank International Atomic Energy Agency's Technical Cooperation Projects SRL 5048, RAS 5078 and INT 5154. We thank Mr. Malinda Dissanayake for assistance in laboratory.

\section{REFERENCES}

Ahn Y., Linder S.W., Veach B.T., Yan S.S., Fernández A.H., Pineiro S.A. \& Cerniglia C.E. (2012). In vitro enrofloxacin binding in human fecal slurries. Regulatory Toxicology and Pharmacology 62(1): 74-84.

DOI: https://doi.org/10.1016/j.yrtph.2011.11.013

Amjad H., Iqbal J. \& Naeem M. (2005). Analysis of some residual antibiotics in muscle, kidney and liver samples of broiler chicken by various methods. Proceedings of the Pakistan Academy of Sciences 42(4): 223-231.

Anderson A.D., Nelson J.M., Rossiter S. \& Angulo F.J. (2003). Public health consequences of use of antimicrobial agents in food animals in the United States. Microbial Drug Resistance 9(4): 373-379.

DOI: https://doi.org/10.1089/107662903322762815

Apata D.F. (2009). Antibiotic resistance in poultry. International Journal of Poultry Science 8(4): 404-408.

Arslan-acaroz D. \& Sozbilir N.B. (2020). Investigation of enrofloxacin and ciprofloxacin residues by LC-MS/MS in chicken liver marketed in Afyonkarahisar. Ankara Universitesi Veteriner Fakultesi Dergisi 67(2): 137-142.

Aslam B., Kousar N., Javed I., Raza A., Ali A., Khaliq T., Muhammad F. \& Khan, J.A. (2016). Determination of enrofloxacin residues in commercial broilers using high performance liquid chromatography. International Journal of Food Properties 19(11): 2463-2470. DOI: https://doi.org/10.1080/10942912.2015.1027922

Attari V.E., Abbasi M.M., Abedimanesh N., Ostadrahimi A. \& Gorbani A. (2014). Investigation of enrofloxacin and chloramphenicol residues in broiler chickens carcasses collected from local markets of Tabriz, North Western Iran. Health Promotion Perspectives 4(2): 151-157. DOI: https://dx.doi.org/10.5681\%2Fhpp.2014.020

Bauditz R. (1987). Results of clinical studies with Baytril in poultry. Veterinary Medical Review 2: 130-136.
Beyene T. \& Tesega B. (2014). Rational veterinary drug use: Its significance in public health. Journal of Veterinary Medicine and Animal Health 6(12): 302-308. DOI: https://doi.org/10.5897/JVMAH2014.0332

Conley Z.C., Bodine T.J., Chou A. \& Zechiedrich L. (2018). Wicked: The untold story of ciprofloxacin. PLoS Pathogens 14(3): e1006805. DOI: https://doi.org/10.1371/journal.ppat.1006805

Dandeniya W.S. \& Caucci S. (2020). Composting in Sri Lanka: Policies, Practices, Challenges, and Emerging Concerns. In: Organic Waste Composting through Nexus Thinking (eds. H. Hettiarachchi, S. Caucci \& K. Schwarzel), pp. 61-89. Springer Nature, Switzerland.

Dandeniya W.S., Herath E.M., Kasinthar M., Lowe W.A.M. \& Jinadasa R.N. (2018). Prevalence of antibiotic resistant bacteria in poultry litter-based manures and potential threats on food safety for carrot (Dacuscarotova). In: Be the Solution to Soil Pollution. Proceedings of the Global Symposium on Soil Pollution, Rome, Italy, 2-4 May. Food and Agriculture Organization of the United Nations, pp. 309-314.

DAPH (2010). Annual Report. Department of Animal Production and Health, Peradeniya, Sri Lanka. Available at http://www.daph.gov.lk/web/images/content_image/ publications/ annual_reports/annual_report_2010.pdf, Accessed 31 May 2021.

DAPH(2019).Annual Report. Department of Animal Production and Health, Peradeniya, Sri Lanka. Available at $h t t p: / / d a p h$. gov.lk/web/images/content_image/publications/annual_ reports/2019/daph_annualReport_9_18_compressed.pdf, Accessed 31 May 2021.

Darwish W.S., Eldaly E.A., El-Abbasy M.T., Ikenaka Y., Nakayama S. \& Ishizuka M. (2013). Antibiotic residues in food: the African scenario. Japanese Journal of Veterinary Research 61(Supplement): S13-S22.

DOI: http://doi.org/10.14943/jjvr.61.suppl.s13

de Assis D.C.S., da Silva G.R., Lanza I.P., Ribeiro A.C.D.S.R., Lana Â.M.Q., Lara L.J.C., de Figueiredo T.C. \& Cançado S.D.V. (2016). Evaluation of the presence and levels of enrofloxacin, ciprofloxacin, sulfaquinoxaline and oxytetracycline in broiler chickens after drug administration. Plos One 11(11): e0166402.

DOI: https://doi.org/10.1371/journal.pone.0166402

De Silva P.H.G.J., Atapattu N.S.B.M. \& Sandika A.L. (2010). A study of the socio-cultural parameters associated with meat purchasing and consumption pattern: a case of Southern Province, Sri Lanka. The Journal of Agricultural Sciences 5(2): 71-79.

Dethlefsen L., Huse S., Sogin M.L. \& Relman D.A. (2008). The pervasive effects of an antibiotic on the human gut microbiota, as revealed by deep $16 \mathrm{~S}$ rRNA sequencing. PLoS Biology 6(11): e280. DOI:https://doi.org/10.1371/journal.pbio.0060280

Dimitrova D.J., Lashev L.D., Yanev S.G. \& Pandova B. (2007). Pharmacokinetics of enrofloxacin in turkeys. Research in Veterinary Science 82(3): 392-397.

DOI: https://doi.org/10.1016/j.rvsc.2006.09.004 
Dissnayake D.R.A. \&Wijewardana T.G. (2005). Indigenous chickens as sentinels for antimicrobial resistance to Escherichia coli in Sri Lanka. Proceeding of the Peradeniya University Research Sessions, Sri Lanka, 10 November, pp. 160.

Dziva F. \& Stevens M.P. (2008). Colibacillosis in poultry: unravelling the molecular basis of virulence of avian pathogenic Escherichia coli in their natural hosts. Avian Pathology 37(4): 355-366.

DOI: https://doi.org/10.1080/03079450802216652

Endtz H.P., Ruijs G. J., van Klingeren B., Jansen W.H., van der Reyden T. \& Mouton R.P. (1991). Quinolone resistance in Campylobacter isolated from man and poultry following the introduction of fluoroquinolones in veterinary medicine. Journal of Antimicrobial Chemotherapy 27(2): 199-208.

DOI: https://doi.org/10.1093/jac/27.2.199

European Commission (2002). Commission Decision 2002/657/EC of 12 August 2002 implementing Council Directive 96/23/EC concerning the performance of analytical methods and the interpretation of results. Official Journal of the European Communities 50: 8-36.

European Commission (2010). Commission Regulation (EU) No $37 / 2010$ of 22 December 2009 on pharmacologically active substances and their classification regarding maximum residue limits in foodstuffs of animal origin. Official Journal of the European Union 15: 1-72.

European Medicine Agency (2012). Baytril 10\% oral solution and associated names: Annex I, II, III, IV. Available at https://www.ema.europa.eu/en/documents/referral/baytril10-oral-solution-associated-names-annex-i-ii-iii-iv_ en.pdf, Accessed 31 May 2021

FDA (2005). Withdrawal of Approval of the New Animal Drug Application for Enrofloxacin in Poultry. Docket number 2000N-1571. Department of Health and Human Services, United States Food and Drug Administration.

Goutard F.L., Bordier M., Calba C., Erlacher-Vindel E., Góchez D., de Balogh K., Benigno C., Kalpravidh W., Roger F. \& Vong S. (2017). Antimicrobial policy interventions in food animal production in Southeast Asia. BMJ 358: 36-41. DOI: https://doi.org/10.1136/bmj.j3544

Gouvêa R., dos Santos F.F., de Aquino M.H.C. \& Pereira V.L. (2015). Fluoroquinolones in industrial poultry production, bacterial resistance and food residues: a review. Brazilian Journal of Poultry Science 17(1): 1-10.

DOI: http://dx.doi.org/10.1590/1516-635x17011-10

Gunarathne L., Fernando R., Munasinghe D.M.S. \& Abeynayake P. (2016). Detection of sulfonamides residues in broiler meat in Sri Lanka. Proceedings of South Asian Symposium on Sustainable Environment Management, 1718 March. Center for Environment Studies, University of Peradeniya, Sri Lanka, pp. 14.

Herath E.M., Dandeniya W.S., Samarasinghe A.G.S.I., Bandara T.P.M.S.D. \& Jinadasa R.N. (2015). A preliminary investigation on methods of reducing antibiotic resistant bacteria in broiler litter in selected farms in mid country, Sri Lanka. Tropical Agricultural Research 26(2): 409-414.
Herath E.M., Palansooriya A.G.K.N., Dandeniya W.S. \& Jinadasa R.N. (2016). An assessment of antibiotic resistant bacteria in poultry litter and agricultural soils in Kandy district, Sri Lanka. Tropical Agricultural Research 27(4): 389-398.

Huff W.E., Huff G.R., Rath N.C., Balog J.M. \& Donoghue A.M. (2004). Therapeutic efficacy of bacteriophage and Baytril (enrofloxacin) individually and in combination to treat colibacillosis in broilers. Poultry science 83(12): 1944-1947.

DOI: https://doi.org/10.1093/ps/83.12.1944

Janecko N., Pokludova L., Blahova J., Svobodova Z. \& Literak I. (2016). Implications of fluoroquinolone contamination for the aquatic environment-A review. Environmental Toxicology and Chemistry 35(11): 2647-2656.

Javadi A., Mirzaie H. \& Khatibi S.A. (2011). Effect of roasting, boiling and microwaving cooking methods on Enrofloxacin residues in edible tissues of broiler. African Journal of Pharmacy and Pharmacology 5(2): 214-218.

DOI: https://doi.org/10.5897/AJPP.9000118

Kalupahana R.S., Kottawatta K.S.A., Kanankege K.S.T., Van Bergen M.A.P., Abeynayake P. \& Wagenaar J.A. (2013). Colonization of Campylobacter spp. in broiler chickens and laying hens reared in tropical climates with low-biosecurity housing. Applied Environmental Microbiology 79(1): 393-395.

DOI: https://dx.doi.org/10.1128\%2FAEM.02269-12

Kalupahana R.S., Mughini-Gras L., Kottawatta S.A., Somarathne S., Gamage C. \& Wagenaar J.A. (2018). Weather correlates of Campylobacter prevalence in broilers at slaughter under tropical conditions in Sri Lanka. Epidemiology and Infection 146(8): 972-979. DOI: https://doi.org/10.1017/S0950268818000894

Karunarathna K.G.R.N., Arulkanthan A. \& Jayasena N.U.A. (2013). Antimicrobial resistance patterns in Escherichia coli of poultry origin in the Kandy district. Proceedings of the Peradeniya University Research Sessions, Sri Lanka, 4 July, pp. 99.

King D. E., Malone R. \& Lilley S.H. (2000). New classification and update on the quinolone antibiotics. American Family Physician 61(9): 2741-2748.

Kirbiš A., Marinšek J. \& Flajs V.C. (2005). Introduction of the HPLC method for the determination of quinolone residues in various muscle tissues. Biomedical Chromatography 19(4): 259-265.

DOI: https://doi.org/10.1002/bmc.435

Kottawatta S.A.K., Van Bergen M.A.P., Abeynayake P., Wagenaar, J.A., Veldman K.T. \& Kalupahana R.S. (2017). Campylobacter in broiler chicken and broiler meat in Sri Lanka: Influence of semi-automated vs. wet market processing on campylobacter contamination of broiler neck skin samples. Foods 6(12): 105.

DOI: https://doi.org/10.3390/foods6120105

Kowalski T.J., Henry M.J. \& Zlabek J.A. (2005). Furazolidoneinduced pulmonary hypersensitivity. Annals of Pharmacotherapy 39(2): 377-379.

DOI: https://doi.org/10.1345\%2Faph.1E080 
Landers T.F., Cohen B., Wittum T.E. \& Larson E.L. (2012). A review of antibiotic use in food animals: perspective, policy, and potential. Public Health Reports 127(1): 4-22. DOI: https://doi.org/10.1177\%2F003335491212700103

Liyanage G.Y. \& Pathmalal M. (2017). Risk of prophylactic antibiotics in livestock and poultry farms-a growing problem for human and animal health. Pharmaceutical Journal of Sri Lanka 7(1):13-22.

Lowe W.A.M., Samarakone T.S., Vidanarachchi J.K., Dandeniya W.S. \& Edirisinghe N. (2019). Antibiotic residue free broiler meat; Prevalence of antibiotic residues in broiler meat and resistant bacteria in poultry litter in Sri Lanka and awareness on antibiotic usage. International Journal of Food and Nutritional Sciences 8(4): 34-40.

Manage P.M. (2018). Heavy use of antibiotics in aquaculture; Emerging human and animal health problems-A review. Sri Lanka Journal of Aquatic Sciences 23(1): 13-27.

Manage P.M. \& Liyanage G.Y. (2019). Antibiotics induced antibacterial resistance. In: Pharmaceuticals and Personal Care Products: Waste Management and Treatment Technology, pp. 429-448. Butterworth-Heinemann, Oxford, UK.

McDermott P.F. et al. (27 authors) (2004). Development of a standardized susceptibility test for Campylobacter with quality-control ranges for ciprofloxacin, doxycycline, erythromycin, gentamicin, and meropenem. Microbial Drug Resistance 10(2): 124-131.

DOI: https://doi.org/10.1089/1076629041310064

Mcleod A., Thieme O. \& Mack S.D. (2009). Structural changes in the poultry sector: will there be smallholder poultry development in 2030? World's Poultry Science Journal 65(2): 191-200.

DOI: https://doi.org/10.1017/S0043933909000129

Ministry of Health and Welfare (2005). Specifications and Standards for Food, Food Additives. Notification no. 499. Ministry of Health and Welfare, Tokyo, Japan.

Mitchell M.A. (2006). Enrofloxacin. Journal of Exotic Pet Medicine 15(1): 66-69.

Moghadam N.R., Arefhosseini S.R., Javadi A., Lotfipur F., Ansarin M., Tamizi E. \& Nemati M. (2018). Determination of enrofloxacin and ciprofloxacin residues in five different kinds of chicken tissues by dispersive liquid-liquid microextraction coupled with HPLC. Iranian Journal of Pharmaceutical Research 17(4): 1182-1190.

Nelson J.M., Chiller T.M., Powers J.H. \& Angulo F.J. (2007). Fluoroquinolone-resistant Campylobacter species and the withdrawal of fluoroquinolones from use in poultry: a public health success story. Clinical Infectious Diseases 44(7): 977-980.

DOI: https://doi.org/10.1086/512369

Nkukwana T.T. (2018). Global poultry production: Current impact and future outlook on the South African poultry industry. South African Journal of Animal Science 48(5): 869-884.

DOI: https://doi.org/10.4314/sajas.v48i5.7

Panzenhagen P.H.N., Aguiar W.S., Gouvêa R., de Oliveira A.M., Barreto F., Pereira V.L.A. \& Aquino M.H.C. (2016). Investigation of enrofloxacin residues in broiler tissues using ELISA and LC-MS/MS. Food Additives \& Contaminants: Part A 33(4): 639-643.

DOI: https://doi.org/10.1080/19440049.2016.1143566

Pena A., Silva L.J.G., Pereira A., Meisel L. \& Lino C.M. (2010). Determination of fluoroquinolone residues in poultry muscle in Portugal. Analytical and Bioanalytical Chemistry 397(6): 2615-2621.

DOI: https://doi.org/10.1007/s00216-010-3819-0

Sarker Y.A., Hasan M.M., Paul T.K., Rashid S.Z., Alam M.N., \& Sikder M.H. (2018). Screening of Veterinary and Animal Research 5(2): 140-145.

DOI: http://doi.org/10.5455/javar.2018.e257

Sattar S., Hassan M.M., Islam S.K.M.A, Alam M., Al Faruk M.S., Chowdhury S. \& Saifuddin A.K.M. (2014). Antibiotic residues in broiler and layer meat in Chittagong district of Bangladesh. Veterinary World 7(9):738-743.

DOI: https://doi.org/10.14202/vetworld.2014.738-743

Seguin M.A., Papich M.G., Sigle K.J., Gibson N.M. \& Levy J.K. (2004). Pharmacokinetics of norfloxacin in neonatal kittens. American Journal of Veterinary Research 65(3): 350-356.

DOI: https://doi.org/10.2460/ajvr.2004.65.350

Sharma P.C., Jain A., Jain S., Pahwa R. \& Yar M.S. (2010). Ciprofloxacin: review on developments in synthetic, analytical, and medicinal aspects. Journal of Enzyme Inhibition and Medicinal Chemistry 25(4): 577-589. DOI: https://doi.org/10.3109/14756360903373350

Shim J.H., Shen J.Y., Kim M.R., Lee C.J. \& Kim I.S. (2003). Determination of the fluoroquinolone enrofloxacin in edible chicken muscle by supercritical fluid extraction and liquid chromatography with fluorescence detection. Journal of Agricultural and Food Chemistry 51(26): 7528-7532. DOI: https://doi.org/10.1021/jf0346511

Singer R.S. \& Hofacre C.L. (2006). Potential impacts of antibiotic use in poultry production. Avian Diseases 50(2): 161-172.

DOI: https://doi.org/10.1637/7569-033106R.1

Smith K.E., Besser J.M., Hedberg C.W., Leano F.T., Bender J.B., Wicklund J.H., Johnson B.P., Moore K.A. \& Osterholm M.T. (1999). Quinolone-resistant Campylobacter jejuni infections in Minnesota, 1992-1998. New England Journal of Medicine 340(20): 1525-1532.

DOI: https://doi.org/10.1056/NEJM199905203402001

Sultan I.A. (2014). Detection of enrofloxacin residue in livers of livestock animals obtained from a slaughterhouse in Mosul City. Journal of Veterinary Science and Technology 5(2): 168.

DOI: https://doi.org/10.4172/2157-7579.1000168

Sureshkumar V. \& Sarathchandra G. (2018). Prevalence of enrofloxacin and its primary metabolite ciprofloxacin residues in broiler meat and organ samples of field origin. Global Journal of Bioscience and Biotechnology 7(3): 324-326.

Tauxe R.V.(2002).Emerging foodbornepathogens.International Journal of Food Microbiology 78(1-2): 31-41.

DOI: https://doi.org/10.1016/S0168-1605(02)00232-5

U.S. Food and Drug Administration (1994). Reviewer Guidance, Validation of Chromatographic Methods, Center for Drug Evaluation and Research, Rockville, USA. 
Wang G.N., Feng C., Zhang H.C., Zhang Y.Q., Zhang L. \& Wang J.P. (2015). Determination of fluoroquinolone drugs in meat by ionic-liquid-based dispersive liquidliquid microextraction-high performance liquid chromatography. Analytical Methods 7(3): 1046-1052. DOI: https://doi.org/10.1039/C4AY02383H

Wickramarachchi A.R., Herath H.M.L.K., JayasingheMudalige U.K., Edirisinghe J.C., Udugama J.M.M.,
Lokuge L.D.M.N. \& Wijesuriya W. (2017). An analysis of price behavior of major poultry products in Sri Lanka. Journal of Agricultural Sciences 12(2): 138-148.

Yorke J.C. \& Froc P. (2000). Quantitation of nine quinolones in chicken tissues by high-performance liquid chromatography with fluorescence detection. Journal of Chromatography $A$ 882(1-2): 63-77.

DOI: https://doi.org/10.1016/S0021-9673(00)00165-5 